\title{
Performance Assessment of a Novel Pyramid Photobioreactor for Cultivation of Microalgae Using External and Internal Light Sources
}

\author{
Zahra Khoobkar ${ }^{1}$, Farshid \\ Pajoum Shariati ${ }^{*}$, Ali \\ Akbar Safekordi' and \\ Hossein Delavari Amrei
}

'Department of Chemical

Engineering, Science and Research Branch, Islamic Azad University,

Simon Bolivar Ave, Tehran Iran, P.O

Box 1477893855, Tehran, Iran

${ }^{2}$ Department of Chemical

Engineering, Faculty of Engineering, University of Bojnord, Bojnord, P.O.

Box 9453155111, Iran

Received: 13 April 2018

Accepted: 31 January 2019

\section{(i) ()}

\section{SUMMARY}

The cultivation of Chlorella sp., the most abundant microalga in the Persian Gulf, took place in a novel pyramid photobioreactor (PBR), a modified version of plate PBR, consisting of four completely separate equal-volume chambers. In this study we used two light sources incident in each chamber: light-emitting diode (LED) at various wavelengths (red, white and blue) of $108 \mu \mathrm{mol} /\left(\mathrm{m}^{2} \cdot \mathrm{s}\right)$ photosynthetic photon flux density as internal lighting, and the same photon flux density for external white lighting. PBR served to study the effects of light sources on chlorophyll a production, maximum specific growth rate $\left(\mu_{\max }\right)$, biomass productivity rate $\left(r_{\mathrm{p}}\right)$ and photon performance. The results showed that the highest chlorophyll a production was obtained under red LED illumination. The highest values for $r_{p^{\prime}} \mu_{\max }$ and photon performance were obtained under white light.

Key words: microalgae, pyramid photobioreactor, photosynthesis, light source

\section{INTRODUCTION}

Green technologies have been developing rapidly in recent years to combat some of the major problems that humans have faced in the 21st century, such as global warming and climate change (1). Production of alternative fuels to meet the growing energy demand of the developing countries can control the alarming effects of environmental pollution and carbon emission of the fossil fuel combustion $(2,3)$. Biomass is viewed as a renewable energy resource which contains chemical energy derived from sunlight via photosynthesis (4).

In photoautotrophic culture, the light photons are the source of energy, in which their properties, including light distribution and spectrum intensity, are essential for microalgal growth. Therefore, specific growth rate, photosynthetic pigment content and the amount of biochemical compounds (such as lipids) can be influenced by light source characteristics (5-9).

Algae as a third generation of biofeedstocks are regarded as a promising energy resource for fuel and chemical production $(10,11)$. Microalgae are microorganisms that exist in the form of the individual cell or in a group of cells with a photosynthesis unit, converting the sunlight using nutrients in the aquatic habitat and $\mathrm{CO}_{2}$ from the atmosphere or some flows such as wastewater or flue gas (12-15). High photosynthesis rate of microalgae promises a versatile feedstock when the growth conditions are well provided $(16,17)$. Although the sunlight is a cheap source of light for the microalgal growth systems, microalgae are capable of producing high-value food supplements like carotenoids, polyunsaturated fatty acids and phycobilins; therefore, the use of artificial light sources like light-emitting diode (LED) is economically feasible (18-20). Moreover, the growth of microalgae requires much smaller arable land area and fresh water than terrestrial biomass (21-23). These merits make microalgae the third generation of versatile feedstock for use as an alternative energy resource. However, there are some limitations in microalgal production and conversion. Considering the production, the diurnal variation of sunlight is a restriction for the production of algae $(24,25)$. Hence, the artificial light can be a good choice for their stable growth. Two major routes for mass production of microalgae are open 
systems and closed photobioreactors (PBRs) (26). Open systems including open ponds face many challenges like strain contamination, water evaporation, and high harvesting cost (27). On the other hand, PBRs are a preferable choice for production of microalgae due to the higher cell density and biomass productivity as a result of better mixing and higher light absorption, less contamination of algae, and accurate control of culture conditions (28). Many types of PBRs and illumination have been investigated for the mass production of microalgae (29-31). Wang et al. (31) studied the effect of different LED lights on the specific growth rate of algae and obtained the highest growth rate using red LED. However, some studies have shown that the optimal growth rate varies among strains $(28,29)$. Also, some tests have been done on the design and geometry of PBRs for better illumination and reaching a more efficient surface area to volume ratio $(16,32,33)$. Pires et al. (34) studied the optimization of PBR design using computational fluid dynamics (CFD) method.

This study investigates the production of Chlorella sp. microalgae found in the Persian Gulf, Iran, using a novel pyramid PBR with a new configuration and illumination in order to maximize algal growth. Also, chlorophyll a (Chl a) production and photon performance values under different light conditions were studied.

\section{MATERIALS AND METHODS}

\section{Microalgal cultivation}

Microalga Chlorella sp. PTCC 6010 was provided by the Iranian Research Organization for Science and Technology. This microorganism is the major microalga found in the northern part of the Persian Gulf, Bushehr province $\left(28.9234^{\circ} \mathrm{N}\right.$, $\left.50.8203^{\circ} \mathrm{E}\right)$, Iran. The high photosynthetic efficiency of Chlorella and its rich oil content justify the research and development of the mass production and commercialization of this strain as a valuable source for biofuel production, especially biodiesel $(35,36)$.

The microorganism was precultivated in four 2000-mL Erlenmeyer flasks with $1000 \mathrm{~mL}$ working volume which were autoclaved (AV5; Azar Pars, Tehran, Iran) separately. For this purpose, $800 \mathrm{~mL}$ of the inorganic medium were inoculated with $1 \mathrm{~mL}$ of strain solution. The Rudic culture medium contained (in mg/L): $\mathrm{NaNO}_{3} 300, \mathrm{KH}_{2} \mathrm{PO}_{4} 20, \mathrm{~K}_{2} \mathrm{HPO}_{4} 80, \mathrm{NaCl} 20, \mathrm{CaCl}_{2} 47$, $\mathrm{MgSO}_{4} \cdot 7 \mathrm{H}_{2} \mathrm{O} 10, \mathrm{ZnSO}_{4} \cdot 7 \mathrm{H}_{2} \mathrm{O} 0.1, \mathrm{MnSO}_{4} \cdot \mathrm{H}_{2} \mathrm{O} 1.5, \mathrm{CuSO}_{4} \cdot 5 \mathrm{H}_{2} \mathrm{O}$ $0.08, \mathrm{H}_{3} \mathrm{BO}_{3} 0.3,\left(\mathrm{NH}_{4}\right) \cdot 6 \mathrm{Mo}_{7} \mathrm{O}_{24} \cdot 4 \mathrm{H}_{2} \mathrm{O} 0.3, \mathrm{FeCl}_{3} \cdot 6 \mathrm{H}_{2} \mathrm{O} 17$, $\mathrm{Co}\left(\mathrm{NO}_{3}\right)_{2} \cdot \mathrm{H}_{2} \mathrm{O} 0.2$ and EDTA 7.5. All chemicals used in this research were from Merck Co. (Darmstadt, Germany) with purity between 98-99.5\% and the culture medium was autoclaved to be sterilized. After precultivation, the microalgae were cultivated in the pyramid photobioreactor (PBR).

\section{Light sources}

In this study, we used two sources of light in the system as internal and external sources. Internal light sources were white, red and blue LEDs. These 18-watt LEDs were placed on the wall of the rectangular column in the centre of the pyramid PBR as internal light source. Besides, for the external light source, four white 18-watt LEDs were used. All LEDs used in this work were made by TCL Lighting Electrical Appliances Co. Ltd. (Huizhou, PR China).

\section{Experimental set-up and PBR construction}

The walls of the PBR constructed for this study were made of acrylic glass with the thickness of $6 \mathrm{~mm}$. The PBR was separated by four black blades ( $4 \mathrm{~mm}$ thickness). The purpose of these separators is to illuminate each of the four chambers with different light sources without interference.

The central light source of the PBR is fixed and placed on a cylindrical poly(methyl methacrylate), i.e. Plexiglas with $12 \mathrm{~cm}$ diameter and $70 \mathrm{~cm}$ height. The distance between the light source and pyramidal PBR face is $20 \mathrm{~cm}$. The pyramid design allows for using internal light as well as external illumination for more efficient light capture and maintaining maximum light intensity for optimum production rate. According to the study of Hu et al. (37) , the walls of pyramid are arranged at a $60^{\circ}$ angle to the base. The working volume of each section was $16 \mathrm{~L}$. Photon flux density at external and internal surfaces of each section was about $108 \mu \mathrm{mol} /\left(\mathrm{m}^{2} \cdot \mathrm{s}\right)$. Only one section did not receive internal light. In order to sterilize the imported air via air pump, an air filter was used for removal of emissions. In order to sterilize the pyramidal PBR, a solution of $\mathrm{NaOH}$ (0.1 M) was used prior to the culture of microalgae.

Fig. 1 shows the schematic representation of the constructed pyramid PBR. As it can be seen, there are 12 different sections: (1) power supply unit to adjust the voltage and ampere of light sources in order to have the same number of photons in all light sources. These LED sources are controlled by a direct current (DC) power supply model PS-305D (Dazheng Co. Ltd, Shandong, PR China), (2) external light sources are located $20 \mathrm{~cm}$ from the PBR, (3) sampling valves are fixed at a point 35

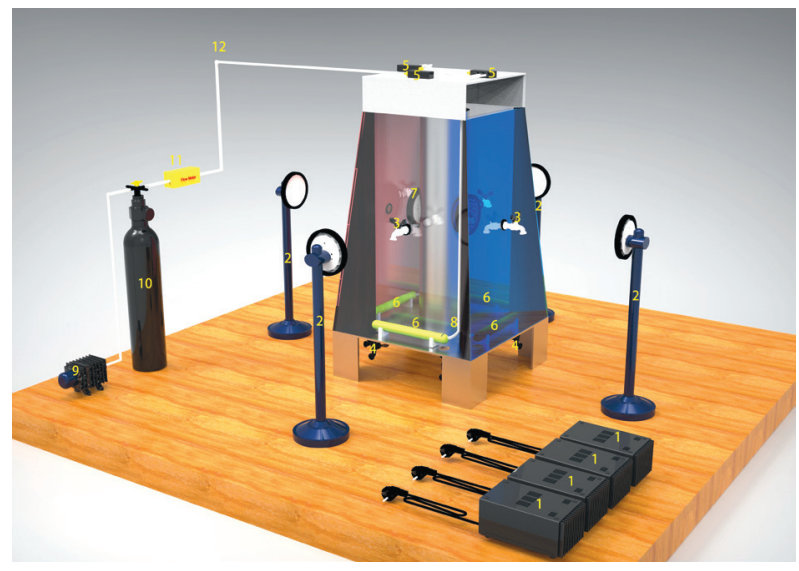

Fig. 1. Experimental set-up of novel pyramid photobioreactor for Chlorella sp. cultivation: 1=power supply, 2=external light source, 3 =sampling valves, $4=$ discharge valves, 5=air intake, $6=$ sparger, $7=$ =internal light source, $8=$ air tubing, $9=$ air pump, $10=\mathrm{CO}_{2}$ reservoir, $11=$ syringe filters, and $12=$ connecting pipe 
$\mathrm{cm}$ from the bottom of each chamber, (4) below each chamber, there are two embedded discharge valves that are used to empty the contents of the PBR, (5) air intake is maintained with the air pump, (6) mixing and aeration of the PBR are accomplished by spargers with a length of $250 \mathrm{~mm}$ and a diameter of $150 \mathrm{~mm}$. These can also be used for $\mathrm{CO}_{2}$ injection into the system, whenever necessary, (7) the internal light sources of the system are LEDs in red, blue and white colours, and one of the chambers does not have an internal light source, (8) the air tubing connects the spargers to the pump, (9) air pump (ACO-500, HAILEA, Raoping, PR China) is used for mixing and aeration, (10) $\mathrm{CO}_{2}$ reservoir can be used to provide the required $\mathrm{CO}_{2}$ whenever needed, (11) 0.45- $\mu \mathrm{m}$ BIOFIL syringe filter (Wenzhou Maikai Laboratory Equipment Co., Ltd, Yueqing, PR China) used between the pump and the inlet tubing for better and clearer air intake and (12) connecting pipe.

\section{Growth parameters of microalgae}

The growth rate of microalgae was determined by measuring the absorbance of the broth at $560 \mathrm{~nm}$ in a double beam UV/Vis spectrophotometer (model V550; Jasco Inc., Easton, MD, USA). Biomass concentration $(x /(\mathrm{mg} / \mathrm{L}))$ was calculated according to Delavari Amrei et al. (29):

$$
x=490 \cdot A_{560 \mathrm{~nm}}
$$

The specific growth rate of microalgae in the broth was calculated using the following equation:

$$
\mu=\frac{\ln \frac{\gamma_{\mathrm{t}}}{\gamma_{0}}}{t}
$$

where $\mu$ is the specific growth rate (day) and $x_{t}$ and $x_{0}$ are the biomass concentration at time $t$ and at the beginning, respectively.

The biomass productivity rate $\left(r_{\mathrm{p}} /(\mathrm{mg} /(\mathrm{L} \cdot\right.$ day $))$ was estimated by the following equation:

$$
r_{p}=\frac{x_{f}-x_{0}}{t_{f}-t_{0}}
$$

where $x_{\mathrm{f}}$ is the biomass concentration at the end of the cultivation $\left(t_{f}\right)$. Photon performance value $(E)$ was also calculated as follows:

$$
E=\frac{r_{\mathrm{p}}}{l}
$$

where $r_{p}$ is biomass productivity and $/$ is the photon flux density that hits the surfaces of the PBR. The value of / with internal lighting was about $216 \mu \mathrm{mol} /\left(\mathrm{m}^{2} \cdot \mathrm{s}\right)$ and without the internal lighting about $108 \mu \mathrm{mol} /\left(\mathrm{m}^{2} \cdot \mathrm{s}\right)$.

In order to investigate the concentration and absorption spectra of pigments, cells were collected in 2-mL centrifuge tubes (D-78532; Andreas Hettich GmbH \& Co.KG, Tuttlingen, Germany), and the pigments were extracted with $2 \mathrm{~mL}$ ethanol overnight in an ice bath. The mixture was centrifuged at $2500 \times g$ for $10 \mathrm{~min}$ to sediment the cell debris. Supernatant liquid was used for the determination of the absorption curve of the pigments using the UV/Vis spectrophotometer (V550; Jasco Inc., Easton, MD, USA). Visible light intensity in lux was measured with a light meter (TES-1330A; TES Electrical Electronic Corp., Taipei, Taiwan). Photon flux density in $\mu \mathrm{mol} /\left(\mathrm{m}^{2} \cdot \mathrm{s}\right)$ was determined by a quantometer (PAR Quantum SKP 215; Skye Instruments Ltd). Finally, the content of chlorophyll a (Chl a) was calculated according to Lichtenthaler and Wellburn (38):

$$
\mathrm{Chl} \mathrm{a}=11.75 \cdot A_{662 \mathrm{~nm}}-2.350 \cdot A_{645 \mathrm{~nm}}
$$

\section{RESULTS AND DISCUSSION}

\section{Effect of light source on microalgal growth}

As mentioned in the previous section, the Rudic culture medium was prepared and Chlorella sp. was cultivated under different lighting conditions to investigate their effect on the microalgal growth. Fig. 2 demonstrates the variations of absorbance of the broth and its $\mathrm{pH}$ during cultivation within 19 days of the experiment. As can be seen in Fig. 2a, the $A$ value of the sample increased gradually during the experiment. Despite the overall increase in the growth rate of the sample, the highest growth was observed on day 11, when $\mathrm{pH}$ was in the range of 8.1-8.2. Fig. $2 \mathrm{~b}$ also illustrates the variations of $A$ and $\mathrm{pH}$ during cultivation of Chlorella sp., but under the blue light. As it shows, by prolonging the time, $A$ gradually increased so that the highest growth rate of the cells was observed at $\mathrm{pH}=7.7$ on day 14 . Furthermore, the growth variation under the white light was approximately the same as under the blue light (Fig. 2c), and the maximum growth rate was observed on day 14 , when $\mathrm{pH} \approx 7.7$.

The final observation in this section is related to the cultivation of Chlorella sp. without the external light source. Fig. $2 \mathrm{~d}$ shows the variations of $\mathrm{pH}$ and $A$ during cultivation of Chlorella sp. without internal LED light. Similar to the previous conditions, here the $A$ value also gradually increased, but there is a significant difference in the maximum $A$ at the end of day 19. When internal light sources were applied, lower number of photons received by the cells could be the main reason for this result.

Microalgae are only capable of receiving photosynthetically active radiation (PAR). This phenomenon is due to intracellular photosynthetic pigments, like chlorophyll $a$ and $b$. These pigments can absorb light in the orange-red spectrum $(600-700 \mathrm{~nm})$, but reflect the green light spectrum (39). The light in the orange and red region causes the increase of microalgal growth rate, therefore in the present study the highest growth rate was observed in the red LED lighting system. This is in accordance with the investigation of Seo et al. (40), who found that the highest growth rate of Chlorella sp. was obtained under the red and blue light. 
a)

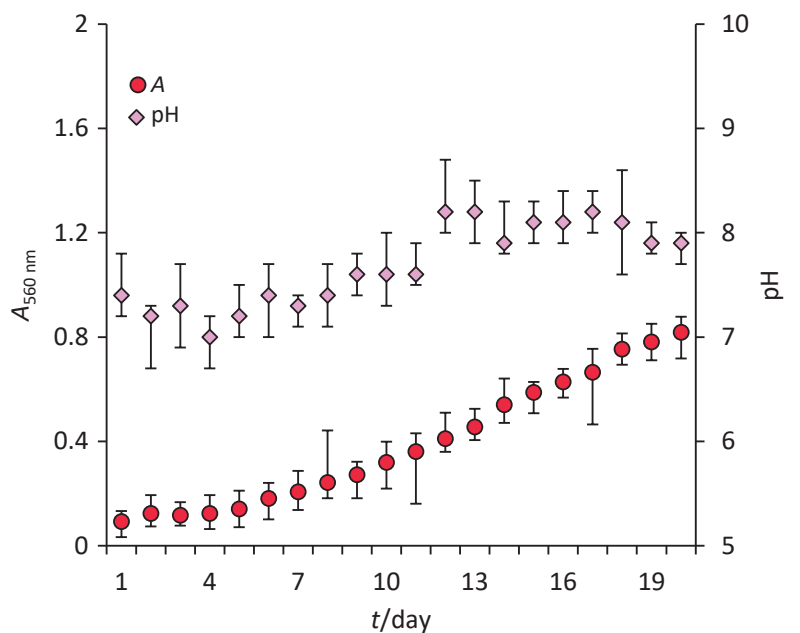

c)

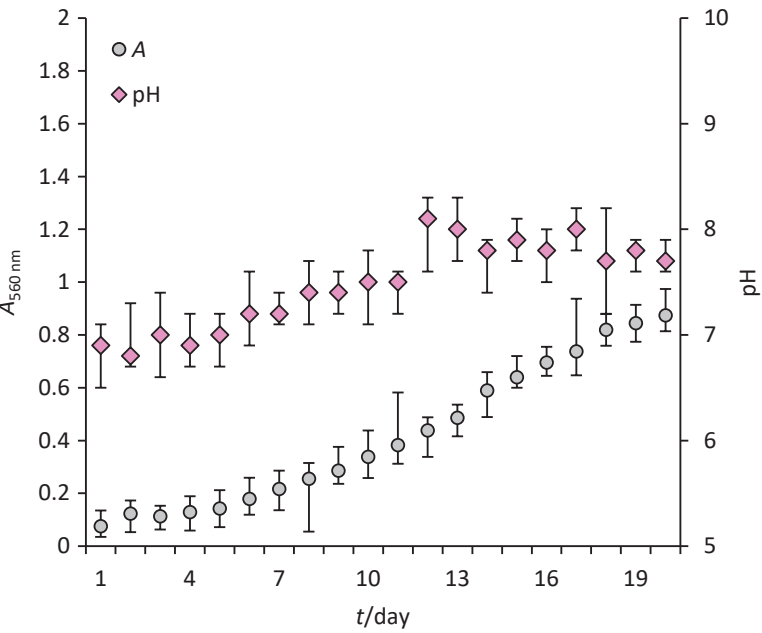

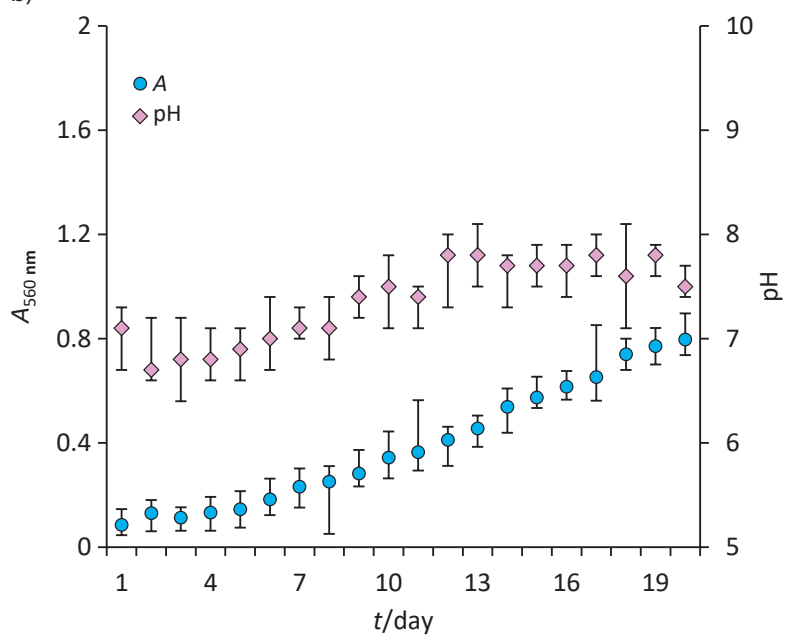

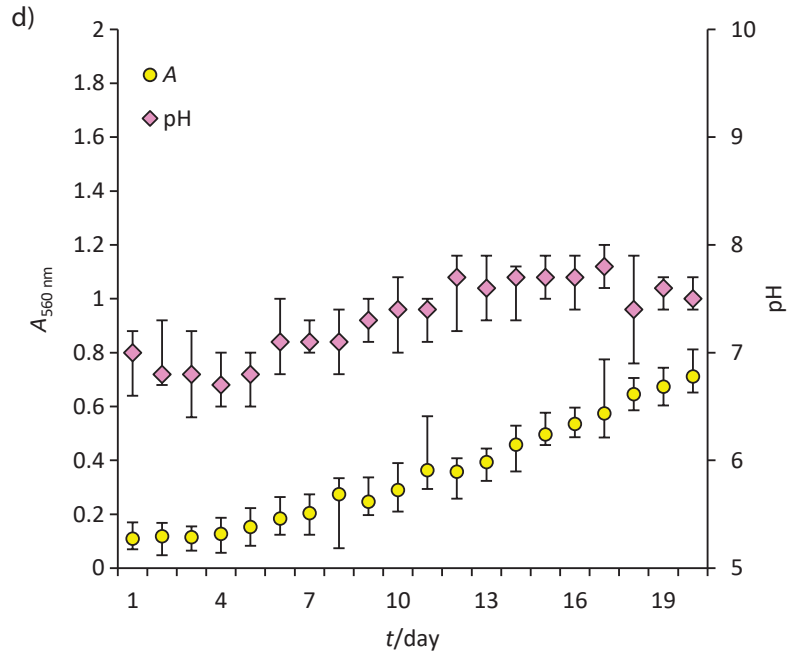

Fig. 2. Changes of absorbance $(A)$ and $\mathrm{pH}$ values during cultivation of Chlorella sp. under: a) red, b) blue, c) white and d) no internal light

\section{Effect of light source on chlorophyll production}

Chlorophyll a (Chl a) content of the microalgae was measured as a parameter that indicates the rate of photosynthesis. As shown in Fig. 3a, in the first week of cultivation, chlorophyll production increased as the growth increased. However, in the second week, the Chl a content started to fluctuate. In the third week, Chl a content decreased drastically, while the growth continued to increase to its highest point on day 19. Moreover, the maximum $\mathrm{Chl}$ a production was observed on day 15. It can be inferred from the trend of $\mathrm{Chl}$ a variation that the red LED stimulates the cells to produce $\mathrm{Chl}$ a only for a short time, while it has no significant effect on the Chl a content in the long term. The results are in agreement with Wang et al. (31).

Fig. $3 \mathrm{~b}$ demonstrates the variation of chlorophyll content under the blue light during 19 days of cultivation. The $\mathrm{Chl}$ a content increased in the first two weeks, then faced extreme fluctuations, and in the third week of cultivation, it decreased.
From Fig. $3 \mathrm{c}$ it is possible to infer that the white LED can promote the chlorophyll content production effectively, which can be contributed to the light wavelength. The maximum $\mathrm{Chl}$ a content was observed on day 12 . Fig. $3 \mathrm{~d}$ shows the variations of chlorophyll and $A$ during cultivation without the addition of internal light source. As shown, the $A$ and $C h l$ a increased gradually without drastic changes, which means that there is not enough llight source for $\mathrm{Chl}$ and biomass production compared to other PBRs. Cultivation without internal source leads to fewer photons received by the cells, which in turn results in lower $A$ and $\mathrm{Chl}$ a at the end of cultivation period than when internal LEDs were used as a light source.

Seo et al. (40) reported that the red light has got higher quantum efficiency than the blue light. Therefore, the growth rate and $\mathrm{Chl}$ a content under corrected red light increased. Accordingly, in this study the $\mathrm{Chl}$ a content under the red light increased, which is due to the high value of the quantum efficiency of the red light. 


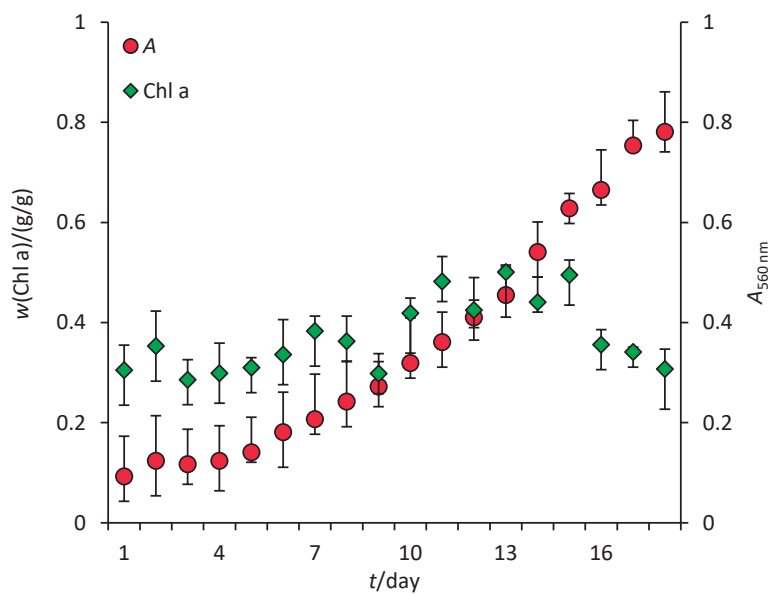

c)

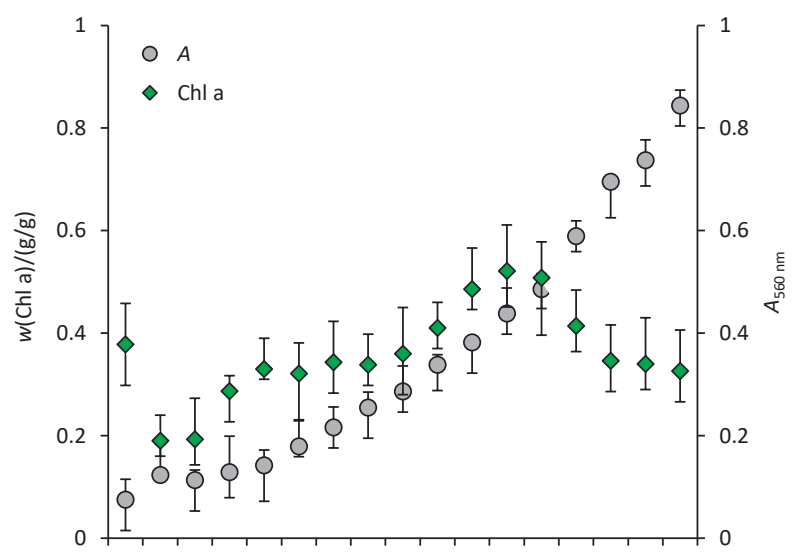

b)

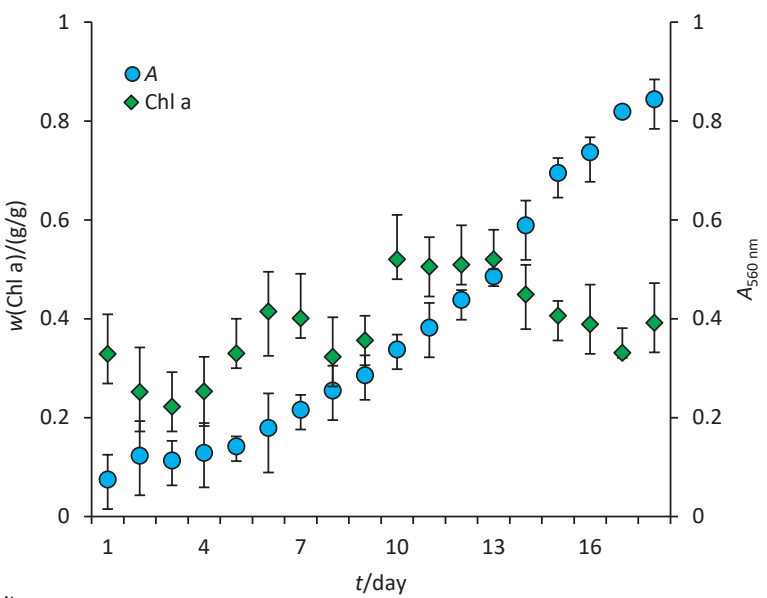

d)

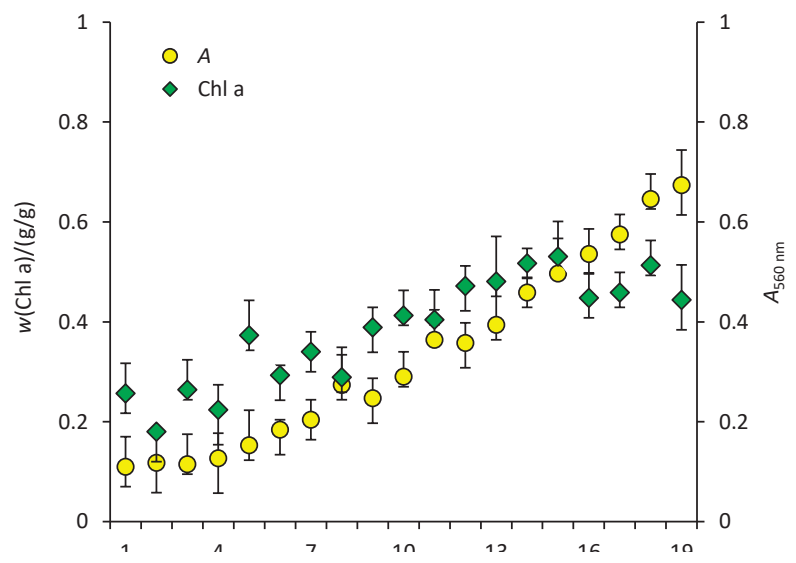

Fig. 3. Changes of chlorophyll a (Chl a) content and absorbance $(A)$ values during cultivation of Chlorella sp. under: a) red, b) blue, c) white and d) no internal light

\section{Effect of light source on the biomass concentration}

Fig. 4 shows the variation of biomass concentration $(x)$ and $A$ during cultivation of Chlorella sp. microalgae in the pyramid PBR. As can be seen, under all lighting conditions, except the one without internal light, the biomass concentration increased. The low value of $x$ under the latter condition is due to the fewer photons received by the cells.

\section{Comparison of growth parameters under different light conditions}

Growth parameters under the different light conditions are given in Table 1. The highest biomass productivity $\left(r_{\mathrm{p}}\right)$ and maximum specific growth rate $\left(\mu_{\max }\right)$ were obtained using white LED as internal light source and the lowest was in the system without internal lighting. White LED consists of a wide range of photons with different amounts of energy, which results in higher biomass production and higher productivity rate during cultivation.

Cultivation using the red LED resulted in higher $\mathrm{Chl}$ a production than under other light conditions. This result is in accordance with Mohsenpour et al. (41), who showed that pigmentation considerably increased under the red light over a period of 14 days with the highest percentages of chlorophylls per gram of biomass. Besides, the system with no internal light had the lowest values of $\mathrm{Chl} a, x, r_{\mathrm{p}}$ and $A$, which corresponds to fewer photons received by Chlorella cells inside the PBR under this condition.

In Table 1, although the growth rate parameters including $r_{\mathrm{p}^{\prime}} \mu_{\mathrm{max}}$ and $x$ under the white LED light were higher relative to the other lighting conditions, these differences compared to the red light were insignificant. Mohsenpour and Willoughby (42) showed that higher growth rate of Chlorella vulgaris biomass was achieved under the corrected red light. Moreover, the high biomass productivity rate was under the red and control (white light) conditions, which is in accordance with this study.

Energy consumption during the cultivation is another crucial factor in this study which has to be investigated. As seen in Table 1, red LED had the lowest power consumption, excluding the condition without internal lighting. However, the difference in the consumed power is not too significant under different lighting conditions. 


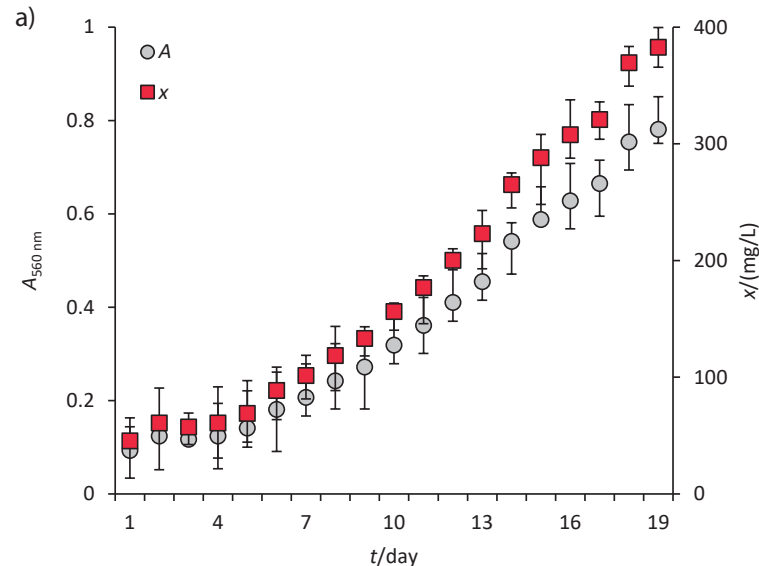

c)

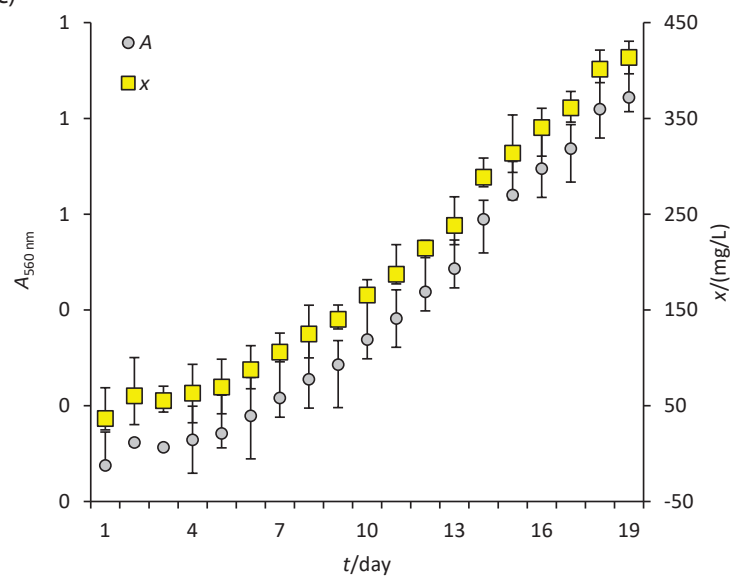

b)

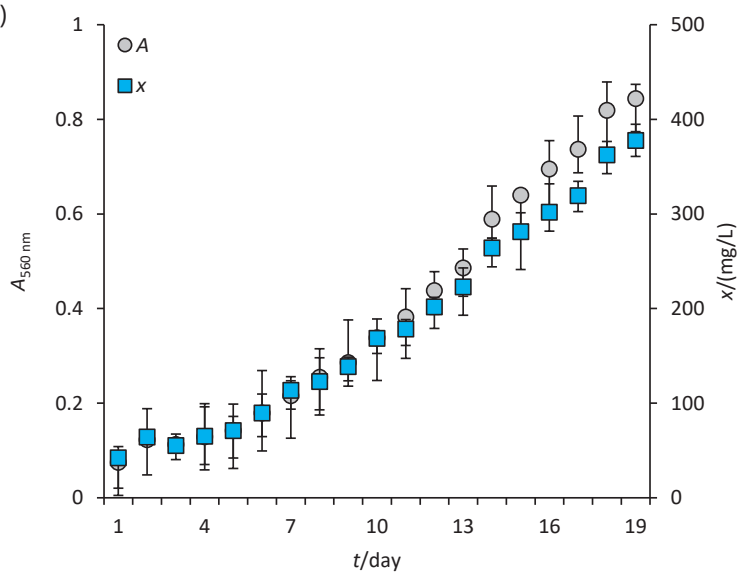

d)

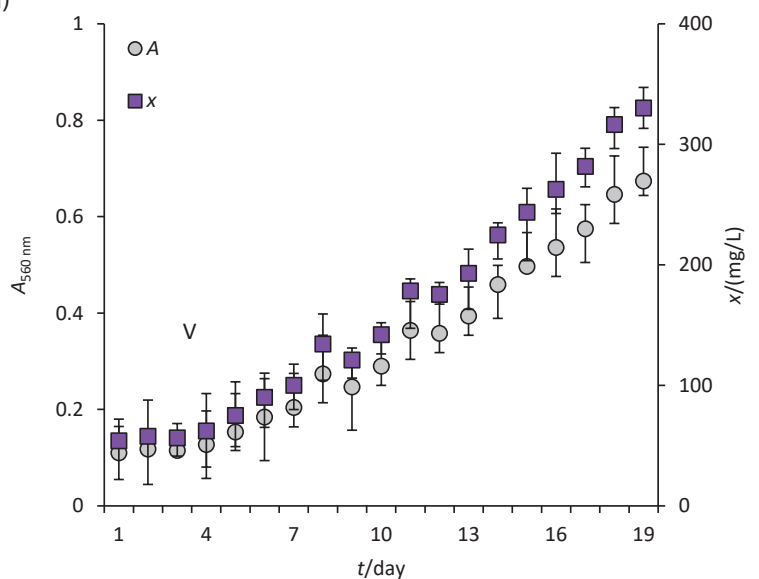

Fig. 4. Changes of biomass concentration $(x)$ and absorbance $(A)$ values during cultivation of Chlorella sp. under: a) red, b) blue, c) white and d) no internal light

Table 1. Growth parameters and power consumption of the microalgae Chlorella sp. cultivation under different lighting conditions

\begin{tabular}{|c|c|c|c|c|c|c|c|}
\hline LED source & $x /(\mathrm{mg} / \mathrm{L})$ & $r_{\mathrm{p}} /(\mathrm{mg} /(\mathrm{L} \cdot \mathrm{day}))$ & $\mu_{\max } /$ day & $w(C h l a) /(g / g)$ & V/V & I/A & P/W \\
\hline Blue & 451 & 15.7 & 0.210 & 2.0 & 23.7 & 0.02 & 33.7 \\
\hline Red & 460 & 15.9 & 0.143 & 2.7 & 16.7 & 0.02 & 33.2 \\
\hline Without internal & 403 & 13.4 & 0.114 & 1.6 & 0 & 0 & 32.0 \\
\hline External & & & & & 27 & 0.33 & 8.9 \\
\hline
\end{tabular}

$x=$ biomass concentration, $r_{\mathrm{p}}=$ biomass productivity, $\mu_{\max }=$ specific growth rate, $\mathrm{Chl}$ a=chlorophyll a ( $\mathrm{g} / \mathrm{g}$ biomass), $V=$ electric potential, $l=\mathrm{electric}$ current, $P=$ electric power

\section{Photon performance values}

Fig. 5 shows photon performance values under different light conditions. It is observable that $E$ in a system without internal lighting was the highest one. In this case, photon flux density was about half of that in the other chambers. Therefore, the growth rate and increase in culture density were lower than under the other lights used in other chambers. Under the white internal light, because of the increase in the growth rate and enhanced system turbidity, $E$ values were lower than without the internal light.

In fact, $E$ value decreased up to $100 \%$ when white light intensity doubled. Also, in the first days of the experiment under the blue internal light, $E$ values were higher than that of the red ones. But after the 14th day, $E$ values were higher

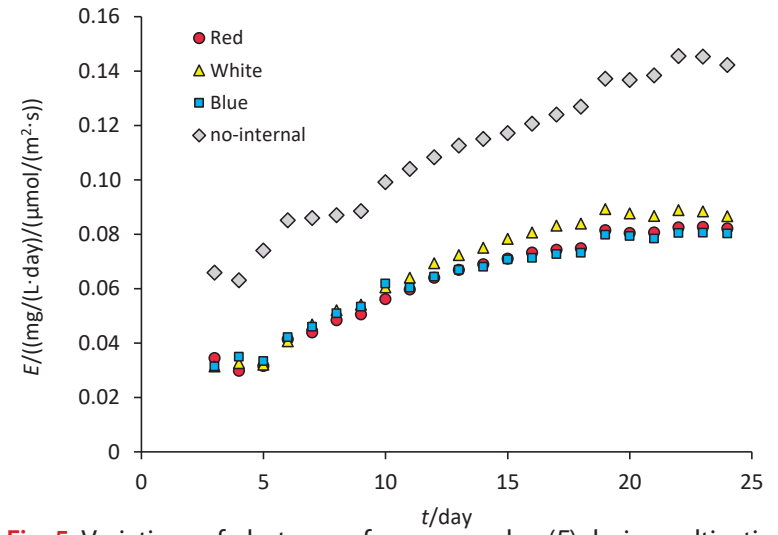

Fig. 5. Variations of photon performance value $(E)$ during cultivation of Chlorella sp. microalgae under red, blue and white light, or without internal light 
under the red light. It is important to note that blue photons have more energy than red ones. Therefore, in the first days of the experiment, the performance value $(E)$ of blue photons was higher than of the red ones. After the 14th day, because of the increase in the turbidity of the systems, the strength of blue light was weaker than that of red light (37). This phenomenon caused a decrease in $E$ values compared to those obtained under red light.

\section{CONCLUSIONS}

This study assessed the cultivation of Chlorella sp. in a novel pyramid photobioreactor (PBR). Operational parameters were measured under four lighting conditions: red, white and blue light, and without the internal light. Red LED lighting resulted in a higher chlorophyll content due to higher stimulation of algal cells at the beginning of cultivation. Besides, white LED lighting resulted in higher biomass productivity, specific growth rate and absorbance values. Internal lighting had a significant effect on biomass production and photosynthesis. All in all, considering the lower energy consumption of red LED, its application is recommended for promoting the photosynthesis of microalgae, while the white LED is recommended for higher biomass production in a longer time period.

\section{ACKNOWLEDGEMENTS}

This work was supported by the Hourateb Co. (Tehran, Iran) and the authors thank the researchers Dr S.K. Alisobhani and Dr M.H. Ghezelayagh for their kind assistance and valuable comments and contributions to this research. Also, thanks to Mr Mahdi Ghezelayagh for computation of our experimental setup and Ms J. Wilson, British native, and Mrs Parisa Keyvan Hossieni and Mrs Mahsa Keyvan Hossieni, our English editors.

\section{REFERENCES}

1. Liu WJ, Jiang H, Yu HQ. Development of biochar-based functional materials: toward a sustainable platform carbon material. Chem Rev. 2015;115(22):12251-85. https://doi.org/10.1021/acs.chemrev.5b00195

2. Jafarian S, Tavasoli A, Karimi A, Norouzi O. Steam reforming of bagasse to hydrogen and synthesis gas using ruthenium promoted $\mathrm{NiFe} / \mathrm{Y}-\mathrm{Al}_{2} \mathrm{O}_{3}$ nano-catalysts. Int J Hydrogen Energ. 2017;42(8):5505-12. https://doi.org/10.1016/j.ijhydene.2016.05.261

3. Norouzi O, Jafarian S, Safari F, Tavasoli A, Nejati B. Promotion of hydrogen-rich gas and phenolic-rich bio-oil production from green macroalgae Cladophora glomerata via pyrolysis over its bio-char. Bioresour Technol. 2016;219:643-51. https://doi.org/10.1016/j.biortech.2016.08.017

4. Nikolaidis P, Poullikkas A. comparative overview of hydrogen production processes. Renew Sust Energ Rev. 2017; 67:597-611.

https://doi.org/10.1016/j.rser.2016.09.044
5. Chrismadha T, Borowitzka MA. Effect of cell density and irradiance on growth, proximate composition and eicosapentaenoic acid production of Phaeodactylum tricornutum grown in a tubular photobioreactor. J Appl Phycol. 1994; 6(1):67-74.

https://doi.org/10.1007/BF02185906

6. Danesi EDG, Rangel-Yagui CO, Carvalho JCM, Sato S. Effect of reducing the light intensity on the growth and production of chlorophyll by Spirulina platensis. Biomass Bioenerg. 2004;26(4):329-35. https://doi.org/10.1016/S0961-9534(03)00127-2

7. Hirata S, Taya M, Tone S. Continuous cultures of Spirulina platensis under photoautotrophic conditions with change in light intensity. J Chem Eng Jpn. 1998;31(4):636-9.

https://doi.org/10.1252/jcej.31.636

8. Matthijs HCP, Balke $\mathrm{H}$, van Hes UM, Kroon BMA, Mur LR, Binot RA. Application of light-emitting diodes in bioreactors: Flashing light effects and energy economy in algal culture (Chlorella pyrenoidosa). Biotechnol Bioeng. 1996; 50(1):98-107.

https://doi.org/10.1002/(SICI)10970290(19960405)50:1<98::AID-BIT11>3.0.CO;2-3

9. Prokop A, Quinn MF, Fekri M, Murad M, Ahmed SA. Spectral shifting by dyes to enhance algae growth. Biotechnol Bioeng. 1984;26(11):1313-22.

https://doi.org/10.1002/bit.260261108

10. Norouzi O, Safari F, Jafarian S, Tavasoli A. Karimi A. Hydrothermal gasification performance of Enteromorpha intestinalis as an algal biomass for hydrogen-rich gas production using $\mathrm{Ru}$ promoted $\mathrm{Fe}-\mathrm{Ni} / \mathrm{Y}-\mathrm{Al}_{2} \mathrm{O}_{3}$ nanocatalysts. Energ Convers Manage. 2017;141:63-71.

https://doi.org/10.1016/j.enconman.2016.04.083

11. Norouzi O, Tavasoli A, Jafarian S, Esmailpour S. Catalytic upgrading of bio-products derived from pyrolysis of red macroalgae Gracilaria gracilis with a promising novel micro/ mesoporous catalyst. Bioresour Technol. 2017;243:1-8. https://doi.org/10.1016/j.biortech.2017.06.072

12. Guo C, Zhou L, Lv J. Effects of expandable graphite and modified ammonium polyphosphate on the flame-retardant and mechanical properties of wood flour-polypropylene composites. Polym Polym Compos. 2013;21(7):449-56.

13. Vassilev SV, Vassileva CG. Composition, properties and challenges of algae biomass for biofuel application: an overview. Fuel. 2016;181:1-33.

https://doi.org/10.1016/j.fuel.2016.04.106

14. Wei N, Quarterman J, Jin YS. Marine macroalgae: an untapped resource for producing fuels and chemicals. Trends Biotechnol. 2013;31(2):70-7.

https://doi.org/10.1016/j.tibtech.2012.10.009

15. Williams PJB, Laurens LM. Microalgae as biodiesel \& biomass feedstocks: Review \& analysis of the biochemistry, energetics \& economics. Energy Environ Sci. 2010;3(5):554-90. https://doi.org/10.1039/B924978H 
16. Ojo EO, Auta H, Baganz F, Lye GJ. Design and parallelisation of a miniature photobioreactor platform for microalgal culture evaluation and optimisation. Biochem Eng J. 2015;103:93-102.

https://doi.org/10.1016/j.bej.2015.07.006

17. Soria-Verdugo A, Goos E, Morato-Godino A, García-Hernando N, Riedel U. Pyrolysis of biofuels of the future: sewage sludge and microalgae - Thermogravimetric analysis and modelling of the pyrolysis under different temperature conditions. Energy Convers Manage. 2017;138:261-72. https://doi.org/10.1016/j.enconman.2017.01.059

18. Blanken W, Cuaresma M, Wijffels RH, Janssen M. Cultivation of microalgae on artificial light comes at a cost. Algal Res. 2013;2(4):333-40.

https://doi.org/10.1016/j.algal.2013.09.004

19. Borowitzka MA, High-value products from microalgae their development and commercialisation. J Appl Phycol. 2013;25(3):743-56.

https://doi.org/10.1007/s10811-013-9983-9

20. Chisti Y. Constraints to commercialization of algal fuels. J Biotechnol. 2013;167(3):201-14.

https://doi.org/10.1016/j.jbiotec.2013.07.020

21. Hanamoto S, Kawakami T, Norihide N, Naoyuki Y, Hiroaki Tanaka. Evaluation of the photolysis of pharmaceuticals within a river by 2 year field observations and toxicity changes by sunlight. Environ Sci Process Impacts. 2014; 16(12):2796-803.

https://doi.org/10.1039/C4EM00448E

22. Nanda S, Dalai AK, Gökalp I, Kozinski JA. Valorization of horse manure through catalytic supercritical water gasification. Waste Manage. 2016;52:147-58.

https://doi.org/10.1016/j.wasman.2016.03.049

23. Singh A, Nigam PS, Murphy JD. Renewable fuels from algae: An answer to debatable land based fuels. Bioresour Technol. 2011;102(1):10-6.

https://doi.org/10.1016/j.biortech.2010.06.032

24. Grobbelaar JU, Factors governing algal growth in photobio reactors: the "open" versus "closed" debate. J Appl Phycol. 2009;21:489-92.

https://doi.org/10.1007/s10811-008-9365-x

25. Tadesse I, Green FB, Puhakka JA. Seasonal and diurnal variations of temperature, $\mathrm{pH}$ and dissolved oxygen in advanced integrated wastewater pond system ${ }^{\oplus}$ treating tannery effluent. Water Res. 2004;38(3):645-54.

https://doi.org/10.1016/j.watres.2003.10.006

26. Slade R, Bauen A. Micro-algae cultivation for biofuels: Cost, energy balance, environmental impacts and future prospects. Biomass Bioenerg. 2013;53:29-38.

https://doi.org/10.1016/j.biombioe.2012.12.019

27. Fu W, Gudmundsson O, Feist AM, Herjolfsson G, Brynjolfsson $\mathrm{S}$, Palsson $\mathrm{B} \emptyset$. Maximizing biomass productivity and cell density of Chlorella vulgaris by using light-emitting diode-based photobioreactor. J Biotechnol. 2012;161(3):242-9.

https://doi.org/10.1016/j.jbiotec.2012.07.004

28. Delavari Amrei H, Nasernejad B, Ranjbar R, Rastegar S. Spectral shifting of UV-A wavelengths to blue light for enhancing growth rate of cyanobacteria. J Appl Phycol. 2014; 26(3):1493-500.

https://doi.org/10.1007/s10811-013-0187-0

29. Delavari Amrei H, Ranjbar R, Rastegar S, Nasernejad B, Nejadebrahim A. Using fluorescent material for enhancing microalgae growth rate in photobioreactors. J Appl Phycol. 2015;27(1):67-74.

https://doi.org/10.1007/s10811-014-0305-7

30. Delavari Amrei H, Nasernejad B, Ranjbar R, Rastegar S. An integrated wavelength-shifting strategy for enhancement of microalgal growth rate in PMMA-and polycarbonate-based photobioreactors. Eur J Phycol. 2014;49(3):324-31.

https://doi.org/10.1080/09670262.2014.919030

31. Wang CY, Fu CC, Liu YC. Effects of using light-emitting diodes on the cultivation of Spirulina platensis. Biochem Eng J. 2007;37(1):21-5.

https://doi.org/10.1016/j.bej.2007.03.004

32. Gómez-Pérez CA, Espinosa J, Montenegro Ruiz LC, van Boxtel AJB. CFD simulation for reduced energy costs in tubular photobioreactors using wall turbulence promoters. Algal Res. 2015;12:1-9. https://doi.org/10.1016/j.algal.2015.07.011

33. Skjånes K, Andersen U, Heidorn T, Borgvang SA. Design and construction of a photobioreactor for hydrogen production, including status in the field. J Appl Phycol. 2016;28(4): 2205-23.

https://doi.org/10.1007/s10811-016-0789-4

34. Pires JCM, Alvim-Ferraz MCM, Martins FG. Photobioreactor design for microalgae production through computational fluid dynamics: A review. Renew Sust Energ Rev. 2017; 79:248-54.

https://doi.org/10.1016/j.rser.2017.05.064

35. Hsia SY, Yang SK. Enhancing algal growth by stimulation with LED lighting and ultrasound. J. Nanomater. 2015;2015: Article ID 531352.

https://doi.org/10.1155/2015/531352

36. Qiang $H$, Zarmi Y, Richmond A. Combined effects of light intensity, light-path and culture density on output rate of Spirulina platensis (Cyanobacteria). Eur J Phycol. 1998; 33(2):165-171.

https://doi.org/10.1080/09670269810001736663

37. Hu Q, Kurano N, Kawachi M, Iwasaki I, Miyachi S. Ultrahigh-cell-density culture of a marine green alga Chlorococcum littorale in a flat-plate photobioreactor. Appl Microbiol Biotechnol. 1998;49(6):655-62.

https://doi.org/10.1007/s002530051228 
38. Lichtenthaler HK, Wellburn AR. Determinations of total carotenoids and chlorophylls $a$ and $b$ of leaf extracts in different solvents. Biochem Soc Trans. 1983;11(5):591-2. https://doi.org/10.1042/bst0110591

39. Jang H, Namgoong Jw, Sung MG, Chang Y, Kim JP. Synthesis and characterization of fluorescent dyes and their applications for the enhancement of growth rate of Chlorella vulgaris. Dyes Pigments. 2018;158:142-50.

https://doi.org/10.1016/j.dyepig.2018.05.003

40. Seo YH, Cho C, Lee JY, Han JI. Enhancement of growth and lipid production from microalgae using fluorescent paint under the solar radiation. Bioresour Technol. 2014;173:193-7. https://doi.org/10.1016/j.biortech.2014.09.012

41. Mohsenpour SF, Richards B, Willoughby N. Spectral conversion of light for enhanced microalgae growth rates and photosynthetic pigment production. Bioresour Technol. 2012;125:75-81.

https://doi.org/10.1016/j.biortech.2012.08.072

42. Mohsenpour SF, Willoughby $\mathrm{N}$. Effect of $\mathrm{CO}_{2}$ aeration on cultivation of microalgae in luminescent photobioreactors. Biomass Bioenerg. 2016;85:168-77.

https://doi.org/10.1016/j.biombioe.2015.12.002 